\title{
The Significance of the Smart Bay Area and Its Construction of the Rule of Law in Guangdong-Hong Kong-Macao
}

\author{
Zehua Feng $^{1}$, Zhengzong Huang ${ }^{2}$ \\ 1. Doctoral Candidate of Graduate School and School of Marxism, Chinese Academy of Social Sciences, Beijing, China \\ 2. School of Social Science, Shenzhen University, Guangdong Province, Shenzhen, China \\ maofengren@163.com,843468955@qq.com
}

\begin{abstract}
In the era of artificial intelligence, the construction of smart bay area in the Guangdong-Hong Kong-Macao Greater Bay Area needs the guarantee of the rule of law to be effectively promoted. To be specific, firstly, the central government should consolidate the legislative foundation for the construction of the smart bay area in the Guangdong-Hong Kong-Macao Greater Bay Area. It is necessary for the central government to set up a leading group for that construction as a coordinating body for smart bay areas. Second, the governments of Guangdong, Hong Kong and Macao actively strive for the central government's authorization of internet operation, and try to innovate local legislation under the constitutional framework to promote the smart data platform of the smart bay area of the greater bay area. Third, the Guangdong, Hong Kong and Macao social organizations shall jointly formulate the social norms for the construction of inter-regional smart bay areas and establish a talent assurance mechanism to enhance the degree of soft law governance of smart bay areas.
\end{abstract}

Keywords-artificial intelligence; Guangdong-Hong KongMacao Greater Bay Area; smart bay area; the foundation of the rule of law; soft law

\section{INTRODUCTION}

The construction of the Guangdong-Hong Kong-Macao Greater Bay Area (GHMGBA) has been positioned as one of the four major bay areas in the world since it was proposed. As a top-level national strategy, it is also positioned as a key platform to boost the integration of Hong Kong and Macao into the overall national development. From the past various versions of GHMGBA cooperation practice, "one country, two systems" are the biggest advantage of the construction of the greater bay area. At the same time, "one country, two systems" may hinder the progress of that construction if some factors of legal isolation are not cleared early. In addition to the obstacles such as institutional isolation and physical isolation, the conflict of the Internet makes it difficult to co-construct and share information between the three places. For one thing, Guangdong, Hong Kong and Macao have formed an invisible Internet firewall for national security since the return of Hong Kong and Macao to maintain. This Internet firewall prevents the normal information exchange between eleven cities in the GHMGBA through the Internet, and has a negative impact on the current economic, political, cultural, social, ecological, scientific and technological exchanges among cities in GHMGBA. For another, for the convenience of the residents of
Guangdong to communicate with Hong Kong and Macao, they use a large amount of over the wall software. In the game of public and private power, individuals, enterprises and the state all consume huge costs. It is paradoxical that under the background of the artificial intelligence era, a number of international Internet enterprises such as Tencent and Huawei have been born, initially forming a high-tech Internet industry cluster centered on Shenzhen. In the current era of artificial intelligence, unless the Internet barriers in the GHMGBA are solved as soon as possible, the further development of GHMGBA will be stagnant. Therefore, the construction of smart bay areas has become the top priority in the planning of GHMGBA. The construction of smart bay area in GHMGBA can provide new methods to solve the urbanization problem, deepening the cross-border cooperation between Guangdong, Hong Kong and Macao, also providing a paragon for the construction of smart bay areas at home and abroad. Many leading Internet enterprises in GHMGBA have their own technology genes, focusing on the development of smart technology and seizing the best opportunity for the construction of intelligent bay area. Under the rapid development trend of the artificial intelligence era, the Fifth China International Smart City Conference was held in Guangzhou in November 2017. The conference has set up the smart bay area development forum of GHMGBA, which reflects the country's attention. In depth, the law is the key to governing a country, and the good law is the prerequisite for good governance [1]. The guarantee of systematic rule of law helps to provide a solid foundation for the construction of smart bay area. In view of this, this paper will provide some feasible paths for the construction of greater bay area smart bay area from the perspective of the rule of law, providing reference for relevant departments.

\section{THE GREAT SIGNIFICANCE FOR THE CONSTRUCTION OF SMART BAY AREA IN GHMGBA}

\section{A. Deepening cooperation and promoting its construction}

The construction of GHMGBA smart bay area provides new ideas for deepening cross-border cooperation between Guangdong, Hong Kong and Macao. In terms of the construction of smart bay area, GHMGBA has a certain gap compared with the world famous bay area. Taking the New York Bay Area as an example, the city's intelligent facilities integrate high-quality human resources and scientific education 
resources, making financial insurance and new service industry the core of the new round of economic growth. Different from the development mode of foreign bay area, the construction of GHMGBA has its particularity. It has cooperation of different legal systems, three independent market systems and two independent customs areas. The economic system, administrative system, financial system, monetary issuing system and economic development planning of the three market systems are completely independent. Differences lead to unclear division of labor in central cities within the region, lack of scientific positioning and coordination mechanism. The degree of cooperation among cities is low, hindering the integrated development of GHMGBA. Based on the problems mentioned above, developed technologies of ICT can be fully utilized to build an intelligent data platform of city cluster. Relying on big data in the intelligent data platform, the current situation of the supply and demand of urban resources in Guangdong, Hong Kong and Macao can be analyzed to improve the administrative efficiency and travel convenience in the region and promote the communication between the mainland, Hong Kong and Macao. All administrative bodies should aim at the community of interests in GHMGBA by the means of intelligent data platform, integrating the resources, carrying out effective urban division, improving the overall development competitiveness of GHMGBA. Thus, the win-win cooperation and prosperity of the cities can be achieved.

\section{B. Promoting regional rule of law and consolidate the "one country, two systems"}

GHMGBA has the particularity of "one country, two systems". Based on the differences in political, economic and social systems between Guangdong, Hong Kong and Macao, the implementation of multilateral cooperation is relatively complicated, which involves a lot of institutional coordination and political issues. Once disputes arise in the region, it becomes more difficult to resolve them. Although there are differences in political and economic systems and social systems, their cultural atmosphere and historical culture are familiar with each other. In recent years, economic integration development in GHMGBA with unprecedented speed. Hong Kong-Zhuhai-Macao Bridge has opened on October 23, 2018. Guangdong, Hong Kong and Macao are cooperating closely with each other in the fields of investment, finance, trade, industry, tourism and transportation. Therefore, it is necessary to promote the construction of the rule of law in GHMGBA and protect the interests of all parties. We will strengthen the rule of law in building the GHMGBA smart bay area, so as to lay a solid foundation for strengthening the "one country, two systems".

\section{Providing experience for the construction of smart bay areas in other bay areas at china and abroad}

The construction of the smart bay area of GHMGBA is mainly committed to building a new mechanism for regional coordination and cooperation. Through institutional innovation and technological integration, it can stimulate the vitality of local regional market, and achieve further coordinated development of the social, economic and cultural development by complementarity, regional linkage and resource sharing. The goal of the construction in GHMGBA is mainly to promote the better cooperation and communication in order to become a world-class bay area. Compared with the construction of the original pan-pearl river delta, the GHMGBA has a wider regional scope and spatial form. Its main purpose is to break down the barriers of administrative division and cross-border separation so as to achieve a high degree of integration within the bay area and to enable the free flow of various resources and elements, intelligent connectivity of infrastructure and coordinated industrial development. At the same time, the smart bay area in GHMGBA is more inclined to internationalization and the development pattern of open mode. GHMGBA can give play to the unique advantages that make use of two marketing systems. In terms of governmental cooperation, intelligence and convenience, we will promote innovation with higher standards, with a new model of regional integration development, providing practical experience for the construction of regional smart bay areas in the bay area at China and abroad.

\section{TOP-LEVEL DESIGN OF THE LEGAL BASIS FOR THE SMART BAY AREA OF GHMGBA}

Firstly, we should consolidate the legislative foundation for the construction of smart bay area in GHMGBA. General secretary $\mathrm{Xi}$ of the $\mathrm{CPC}$ central committee stressed that all major reforms should be based on law [1]. Obviously, the major issue involving GHMGBA cooperation: the construction of smart bay area is bound to require the formulation of unified legislative norms to provide the basis for the implementation of relevant mechanisms. It should be based on the actual situation of construction, and the National People's Congress should make a special decision on the authorization, granting the governmental cooperation power of Guangdong, Hong Kong and Macao so as to make clear the scope and mode of implementation and clarify the legal binding issues of such matters as the construction of the smart bay area jointly by Guangdong, Hong Kong and Macao. This is the commonly method for Chinese legislation practice. The legislation system applies in the big bay area construction may be said the superior strategy. The legal document issued by the National People' s Congress (NPC), rather than the standing committee of NPC, is due to the fact that the inter-governmental cooperation has gone far beyond the existing legal framework. There are many undefined blank areas that even affect the special administrative region system. In accordance with the provisions of China's legislative law, it is in line with China's constitutional system of NPC, the most powerful body in charge of constitution, which defining the legitimacy of the construction of GHMGBA.

Secondly, a coordinated organization for the construction of smart bay areas under the leadership of the leading group of GHMGBA should be established. For any mechanism to be effective, it needs to be implemented by the institution. And for any institution to fulfill its responsibilities and missions, it needs the mechanism to guarantee [2]. As in the past, if cooperative planning did not involve harmonizing institutions of high rank, the result would be to little effect. From a comprehensive view of China's national institutional system, it can be seen that China does not have a special regional cooperation and coordination agency, which brings a lot of 
inconvenience to the construction of the smart bay area. With the deepening of cooperation, the leading group for the construction of GHMGBA was formally established in August 2018, which means that the inter-regional coordination agencies will have corresponding platforms to operate. At present, except for the two chief executives of Hong Kong and Macao, other members of the leading group are all state leaders All the members hold multiple positions, which can only fundamentally grasp the main direction of the establishment of GHMGBA without specific concern. In order to better promote the construction of smart bay area, GHMGBA needs to set up the coordination organization for the construction of GHMGBA smart bay area. Under the agency of coordination, it is necessary for cities to give play to the original industrial advantages and to form a benign competitive situation that complements and supports each other. Due to the different administrative levels of cities, the central government can be responsible for unified coordination. The construction of GHMGBA smart bay area is a major reform, which can be built by the leading group authorized by the standing committee of NPC. The establishment of a unified coordination mechanism is to facilitate the cities in the constructing process of a unified platform for consultation. The reason why it should be authorized by the standing committee of the National People's Congress is that many existing major legislative reforms must be led by a high-level power. The state council can not handle this legislative authority along. With the constitutional level, the standing committee of NPC is the institution that exercises the highest power of the state when the NPC is not in session so that it can deal with various emergencies in GHMGBA. In addition, in order to pool legislative wisdom and give consideration to the interests of all parties involved, the members of the coordination bodies for the construction of GHMGBA smart bay area should include representatives from the legislative commission of the standing committee of NPC, the national development and reform commission, the Hong Kong and Macao office of the state council, the Standing Committee of the People's Congress of Guangdong province, the government of the Hong Kong and Macao special administrative regions. With odd number, the number of representatives should be less than 15 . The majority should be adopted as the principle when voting matters are decided.

\section{LOCAL LEGISLATION INNOVATES MULTIDIMENSIONAL PATH OF CONSTRUCTION OF GHMGBA SMART BAY AREA}

Firstly, the governments of Guangdong, Hong Kong and Macao need to actively seek the central government's authorization for Internet operations. Smart bay areas under artificial intelligence mainly rely on Internet technology. If the Internet operation has not obtained sufficient legislative authorization, the construction concept will become an armchair work. Furthermore, it is necessary for Guangdong, Hong Kong and Macao to seek the central government's authorization for Internet operation in promoting the construction of smart bay areas, because GHMGBA spans three jurisdictions and three customs tax zones. After specific authorization, the legislative direction in Guangdong, Hong Kong and Macao is to cancel the Internet firewall. Local governments conduct a wide range of Internet information circulation in the areas of economy, education in order to guarantee the Internet information exchange freely between various regions in GHMGBA, providing good Internet services for enterprises and residents.

Secondly, Guangdong, Hong Kong and Macao should innovate the forms of local legislation and cooperation under the constitutional framework and promote the construction of smart bay areas. China should actively promote the formulation and application of the model law in the construction of GHMGBA smart bay area. In order to solve the legal conflicts peacefully among internal members, some international organizations or countries often adopt model laws or similar legislative methods. With promoted the smooth operation of the economic and social development policies of the member states, EU generally establish common guidelines. Member states draw up their annual action plans in accordance with the guidelines. Afterwards, EU will regularly review the best practices of the action plan and encourage other member states to learn from each other [3]. Each state of the United States has independent legislative power, which protected their own interests by trade barriers in the history. After the bitter experience, the United States adopts the model law for the reference of state legislatures so as to solve the conflicts of state laws, such as Uniform Commercial Code and National Environmental Policy Regulations. Professional organizations such as the National Committee for the Unification of State Laws, American Law Association and American Bar Association play an important role in promoting the model law [4]. The GHMGBA can learn from the experience of regional integration governance from foreign country. Specifically, with the leadership of the legislative coordination body of the greater bay area, the central government commissioned a number of cross-border legal experts and representatives of trade associations to form a drafting team in different fields to formulate a model law in line with the actual situation of GHMGBA. Under the guidance of the model law, the legislatures, trade associations and other organizations of all parties work out the norms that consistent with the basic spirit of the central government in order to lay a solid legal foundation for the construction of smart bay areas. At the same time, the cooperative parties and the public can propose amendments to the lagging model law. The model law enactment institutions can combine the abolishment, establishment, reform and interpretation according to the relevant opinion of amendments, and finally form a positive interactive atmosphere of legislative coordination and model law. What's more, the completion degree and quality of service for the construction of smart bay area in GHMGBA will be recorded into the assessment indicators for the administrative public officials. The assessment mechanism will be innovated to improve the service quality of the construction of smart bay area, including: (1) Introducing the third party assessment. The administrative assessment in GHMGBA can be conducted by experts and publics; (2) Publicizing and procedural contents should be increased. In the content of the assessment indicators, we should increase the transparent indicators and procedural indicators for the construction of smart bay areas. Specifically, the construction of smart bay areas should conform to the openness of administrative information, convenience of administrative services and procedural administrative affairs. It 
is still difficult for the Chinese government to carry out the examination of Hong Kong and Macao affairs as public officials in Guangdong province, especially the examination power belongs to the state authority. However, the pilot work in GHMGBA has possibility and feasibility. As a national strategy, GHMGBA involves a lot of affairs related to Hong Kong and Macao. Therefore, it is highly possible for relevant construction affairs to be included in the assessment index range of officials.

Thirdly, the governments of Guangdong, Hong Kong and Macao should build an intelligent data platform. The intelligent data platform includes two parts. For one thing, the construction of the intelligent data platform for government in GHMGBA is the core project of the E-government platform in Guangdong, Hong Kong and Macao. Intelligent government data include regional joint examination and approval, online tax filing, social security, document exchange, online conference, etc. When the platform is built, residents of any city in GHMGBA can conduct relevant administrative and judicial affairs online, reducing barriers between the information flow of different websites. For another, the construction of intelligent data platform of life is an important project for the convenient public transportation in Guangdong, Hong Kong and Macao. Intelligent life data include intelligent community, medical treatment, travel, mobile phone card, etc. At present, nine cities in Guangdong can use WeChat to pay for bus, subway, taxi, high-speed rail, etc., while the payment of transportation in Hong Kong and Macao still stay at Octopus and cash. This is not good for the communication of Ecommerce. Therefore, with the efforts of the coordination agencies, the intelligent life data platform can provide residents of any city in GHMGBA with convenient information and working platform such as basic necessities of life, house, medical treatment, education, etc.

\section{THE ROAD OF SOFT LAW FOR SOCIAL ORGANIZATIONS} TO PARTICIPATE IN THE CONSTRUCTION OF GREATER BAY AREA

\section{SMART BAY AREA}

Firstly, social organizations of Internet in GHMGBA jointly formulate social norms for the construction of interregional smart bay area. The market-driven is one of the cooperation principles of the Agreement on Deepening the Cooperation between Guangdong, Hong Kong and Macao to Promote the Construction of the Greater Bay Area. In order to fully flow and optimize the allocation of various production and living factors in the greater bay area, the cooperative parties must give full play to the decisive role of the market in the allocation of resources. The way of market allocation of resources is represented by the public authority oriented by market operation rules, and respects the role of market participants in practice through industry norms, trading habits and other soft laws. Considering the foreign experience, the long-term rule of hard law has restricted the flexibility of the governance of EU member states. Since the 1990s, EU has established a transparent mechanism of coordination and conducted effective public governance by giving play to the role of soft law in integration [5]. Compared with other regions in China, GHMGBA has the highest degree of opening-up and marketization so that it has inherent advantages in promoting the formulation and application of soft law. The application of soft law helps all parties better to play the role of market. Various associations in GHMGBA are set up to promote the construction of smart bay areas, especially the joint establishment of regional associations that can span Guangdong, Hong Kong and Macao. The inter-regional association can establish industry standards, which can be effective across Guangdong, Hong Kong and Macao, forming regional rules of GHMGBA. Some matters requiring the certification of the central authorities need to be coordinated by departments such as the National Development and Reform Commission to authorize the implementation. To sum up, marketization is a key to solve the construction of the smart bay area of GHMGBA. All parties in cooperation should make full use of this key and actively promote the formulation and application of soft law in GHMGBA.

Secondly, we should establish a talent guarantee mechanism for smart bay areas. There are two ways to establish the talent resource mechanism of smart bay area by social organizations. For one thing, universities in GHMGBA carry out education cooperation to jointly cultivate talents. Colleges and universities can establish an information platform for talent exchange so as to improve the training, teaching and research team for the sharing of scientific resources and mutual cooperation. $\mathrm{Li}$, the president of Shenzhen University, proposed the establishment of "joint university of GHMGBA" in the "two sessions" of 2018. As a good path of cooperation for scientific resources, it is a proposal of great value to the talent cultivation of smart bay area, which is worth further discussion by the governments of Guangdong, Hong Kong and Macao before putting it into practice. For another, Guangdong, Hong Kong and Macao social organizations of Internet cooperate in priority areas such as medical science and technology and artificial intelligence to build innovative platforms together, promoting Hong Kong and Shenzhen to fully develop Nansha district in Guangzhou, making full use of Hong Kong's internationalization to attract international highend talents. Social organizations can enquire the administrative department of GHMGBA in the form of legislative proposals, NPC's deputies or CPPCC members' proposals, etc. That talents in the smart bay area can enjoy the benefits of social security, such as cross-boundary carrying, convenient entry and exit, and preferential individual income tax, so as to solve their worries.

\section{CONCLUSIONS}

The age of artificial intelligence is an information age that liberates human hands and facilitates human life. The key to the rapid flow of production factors in GHMGBA is the convenience of Internet communication. The era of artificial intelligence makes inter-regional communication close at hand. The circulation of various production factors gradually breaks the institutional and physical isolation. It is necessary for GHMGBA to build a smart bay area in order to make better use of various dividends in the information age and link Guangdong, Hong Kong and Macao through the Internet platform, letting all kinds of production factors be co-built and shared on the Internet as much as possible. At the same time, it is necessary for GHMGBA to establish a systematic legal 
guarantee path so as to build the smart bay area more stable and orderly. In a word, building GHMGBA smart bay area through the rule of law as soon as possible is an important direction for promoting the construction of GHMGBA. It is a cornerstone for deepening cooperation for the rule of law in Guangdong, Hong Kong and Macao.

\section{ACKNOWLEDGMENT}

This work was supported by the Major Projects of Philosophy and Social Science Foundation of China in 2014 "Study on the Relevant Mechanisms for the Implementation of the Basic Law of Hong Kong and Macao" under Grant No.14ZDC031.

\section{REFERENCES}

[1] "Decision of the CPC Central Committee on Comprehensively Advancing Several Major Issues Governing the Rule of Law," People's Daily, 2014-10-29.

[2] Z. Zuixin, "A Theoretic Construction of the Regional Legislature for the GHMGBA," Local Legislation Journal, vol. 3, issue 4, pp. 11-20, 2018.

[3] Z. Zuixin, "Preliminary Study on the Legal Governance Mode of Regional Integration," Journal of Guangdong Institute of Public Administration, vol. 23, issue 3, pp. 44-48, 2011.

[4] Z. Tao, "The Theoretical Basis of the Demonstration Method and its Application in China," Studies In Law and Business, vol. 89, issue 3, 2002.

[5] W. Ziling, "Study of Soft Law in Close Cooperation between Guangdong, Hong Kong and Macao," Academic Search for Truth and Reality, vol. 242, issue 4, 2017. 